\title{
Assessment of epidemiological obesity among adults in EU countries
}

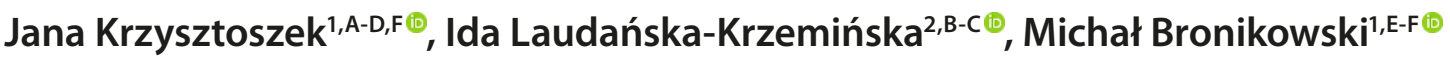 \\ ${ }^{1}$ Department of Didactics of Physical Activity, University of Physical Education, Poznan, Poland \\ ${ }^{2}$ Department of Physical Activity Study and Health Promotion, University of Physical Education, Poznan, Poland \\ A - Research concept and design, B - Collection and/or assembly of data, C - Data analysis and interpretation, \\ $D$ - Writing the article, E - Critical revision of the article, F - Final approval of article
}

Krzysztoszek J, Laudańska-Krzemińska I, Bronikowski M. Assessment of epidemiological obesity among adults in EU countries. Ann Agric Environ Med. 2019; 26(2): 341-349. doi: 10.26444/aaem/97226

\begin{abstract}
Introduction. Obesity is a serious health problem in nearly all regions of Europe. During the last four decades, the percentage of obese people increased four times among men and twice among women, reaching a global epidemic scale as the biggest health-related issue in the developed and developing countries.

Objective. The aim was to assess the epidemiological situation of obesity, according to gender among adults in Europe, compared with other regions and selected worldwide countries, as well as to devise a forecast for the near future based on analysis results.

Materials and method. An overview was performed of the World Health Organization (WHO) statistical database in 1999-2016, concerning obesity prevalence among people over the age of 20 across 28 countries of the European Union. A forecast for the years 2020 and 2030 was prepared by evaluation of gradients for trendline equations. Moreover, some of the world regions, as well as individual countries, five per region, were collated and analyzed to prepare the forecast.

Results. The percentage of obese people in the countries of the European Union continues to increase every year. The dynamics of obesity growth in Europe is greater for men than for women (3.09\% per year vs. $1.92 \%$ per year). With the growth rate remaining at the estimated level, in 2030 there will probably be more obese men (38.1\%) than women (32.7\%) in Poland, and in Europe likewise $-36.6 \%$ and $32.0 \%$, respectively.

Conclusions. Obesity has become a major epidemiological problem and an undisputable health problem not only in Poland and other European countries, but worldwide.
\end{abstract}

\section{Key words}

obesity, adults, Europe, evaluation studies, epidemiology

\section{INTRODUCTION}

Obesity is a serious health problem in nearly all parts of Europe. During the last four decades, the percentage of obese people increased four times among men and twice among women [1], reaching a global epidemic scale and the largest health-related issue in the developed and developing countries [2]. The severity of the obesity problem varies between countries, but affects people of any age, gender or social group. It contributes to the increase in mortality rate worldwide, as a more frequent cause of death than underweight or malnutrition [2]. At least 3.5 million people worldwide die every year due to overweight and obesity [3], with over one million deaths in Europe alone $[3,4]$ and affects approximately 12 million patients annually. Obesity-related comorbidities add to this number and lead to other adverse consequences for health and psychosocial life.

According to the 2014 data of the World Health Organization (WHO), over 2.3 billion people aged 18 years and above worldwide are overweight; of these, 700 million are obese [3]. This means that $39 \%$ of the global adult population have an overweight problem, of which $11 \%$ of men and $15 \%$ of women are affected by obesity. In Europe, the number of

Address for correspondence: Jana Krzysztoszek, Department of Didactics of Physical Activity, Poznan University of Physical Education, Poznan, Poland e-mail: jana.krzysztoszek@gmail.com

Received: 24.08.2018; accepted: 01.10.2018; first published: 26.11.2018 diagnosed obesity cases is between 19\% (Denmark) and 31\% (Malta) [5]. In the UK, the Department of Health forecasts that should the present trend hold, then by 2050 average life expectancy for men will be shortened by five years [5].

According to the WHO, obesity is an abnormal or excessive accumulation of adipose tissue which may contribute to a significant deterioration of health [2]. It is a chronic disease increasing the risk of developing other pathological conditions, and comorbid with such other pathological conditions. Among adults, such conditions include: type 2 diabetes ( $80 \%$ of cases), ischemic cardiac disease $(35 \%$ of cases), hypertension (55\%) [4], brain strokes, gall bladder disorders, dyslipidaemia, insulin resistance, sleep apnea and some types of cancers. Consequently, it is a cause of premature death and psychoemotional disorders [2]. Calle E. et al. [6] calculated that persons with a BMI above $40 \mathrm{~kg} / \mathrm{m}^{2}$, overall mortality due to cancer increases by $52 \%$ in men and $62 \%$ in women. It is particularly high for some cancers - mortality rate increased by $525 \%$ for uterine cancer in women, and by $325 \%$ for hepatic cancer in men [6].

Excessive body weight, apart from increasing mortality, also leads to disability and poorer quality-of-life [7-12], and in turn, its treatment entails serious economic consequences and places a burden on public healthcare systems. The direct cost of treatment of obesity-induced diseases in adults in Europe has been assessed at above 7\% [13] of total healthcare costs, which is comparable to the costs associated with the treatment of neoplastic diseases. 


\section{OBJECTIVE}

The aim of this paper was to assess the epidemiological situation of obesity among adults according to gender in EU countries, compared to other regions and selected countries worldwide. Additionally, changes in obesity prevalence over time were analyzed and forecasts for the nearest future were devised based on the analysis results.

\section{MATERIALS AND METHOD}

An overview of the WHO Global Infobase, the main statistical bank for medical and sanitary data collected by WHO, was performed for the period 1999-2016 in terms of obesity prevalence among adults in EU countries, in all regions and selected countries of the world.

Percentages of obese persons over the age of 20, were collated and analyzed for men and women separately in the EU28 for the years 1999-2009. The percentages for 2010-2016 were collated separately because of the changed age of the study subjects. Obesity increasingly affects young people, which is why as of 2010 the data recorded in the WHO Global Infobase concern people aged over 18. Gradient values of trendline equations reflecting the directions of changes in obesity prevalence in individual countries were determined using a simple linear regression model, and forecasts for 2020 and 2030 were prepared. Various regions of the world, Africa, North and South America, South-East Asia, Middle East, Western Pacific, and Europe, and 5 countries representative for every region, were also collated and analyzed with a forecast prepared. Statistical analysis was carried out using Statistica 10.0 software.

\section{RESULTS}

To illustrate the epidemiological situation of obesity in EU countries, data from WHO database were analyzed. Table 1 lists obesity rates (in \%) in 1999-2009 for men and women aged over 20, for the EU28 in percentage values.

Analysis of the presented data shows that the percentage of obese people in EU countries, except for women in the UK and Italy, continues to increase annually. The differences between genders in individual EU countries, however, are small. The difference between the lowest and the highest rates in men and women was 3.4 percentage points. In 1999, the lowest rate for men was found in Estonia at 25.4\%, while for women it was $25.0 \%$ in Estonia and France, which means that 18 years ago at least 1 in 4 adults in the EU (over the age of 20) were obese. Eight years ago, in 2009, Romania had the lowest percentage of obese men $(25.7 \%)$ and Italy of women (25.2), while the Czech Republic had the highest percentage of obese men (28.4\%) and Malta of women (27.9\%). Note that both the lowest and the highest obesity rates are better for women than for men, $25.2 \%$ vs. $25.7 \%$ and $27.9 \%$ vs $28.4 \%$, respectively. The difference between the genders in both cases was 0.5 percentage point. This does not seem very significant, but in terms of multimillion communities in the EU, it means an outnumbering by thousands of people. Analyzing further the differences in obesity percentages between genders, it must be noted that globally in the EU28 average obesity rate for men (27.1\%) was higher in 2009 than the average rate for women $(26.3 \%)$ by 0.9 percentage point. Moreover, in only 7 countries out of the EU28, Belgium, Denmark, Finland, the Netherlands, Luxemburg, Germany and Sweden, there were fewer obese women than men. Regression analysis describing the relationship between the year and percentage of obese people in EU countries (Tab. 4; Fig. 1) showed that, taking into account the differences in 1999 between the analyzed countries, women had an average lower rate by $0.2 \%$ of obese women, compared to men $(-0.9 \%-1.1 \%)$, and in all countries there was an annual increase by $0.1 \%$ of obese people.

In terms of gender, it is also noteworthy that the dynamics obesity growth in Europe is greater for men than for women (3.1\% per year vs. $1.9 \%$ per year). The smallest increase in the percentage of obese men in the study period was observed in Italy and France (by $0.7 \mathrm{pp}$ ) and the largest in Estonia (by $1.3 \mathrm{pp}$ ). Among women, on the other hand, the UK was the only EU country to see a decrease in the analyzed percentage by $0.1 \mathrm{pp}$. In Italy, following a period of increases of the analyzed percentage, a decrease was observed in 2003 and held until 2009, eventually achieving a level identical to that observed in 1999.

Obesity rates in Poland in 1999 were identical for both genders. Growth rate over the study years was larger among men, thus in 2009, there were slightly more obese men than obese women (difference of $0.5 \mathrm{pp}$ ).

Thirteen countries had over-average values for men $(27.1 \%)$ and 16 countries for women (26.3\%). Within the EU, average obesity rates were exceeded for both men and women in the following countries: the Czech Republic, Finland, Spain, Ireland, Luxemburg, Germany, Slovenia, UK, Cyprus, Lithuania, Hungary, and Malta.

Analysis of data for 2010-2016 (Tab. 2), shows that the growing trend from the previous years was maintained. In all the EU28, obesity prevalence in 2016 was higher than in 2010 , both among women and men aged $\geq 18$ years. The lowest obesity rates were found among men in Portugal and Slovenia, and among women in Denmark, where they were lower than the lowest rate for men by $2.5 \mathrm{pp}$. The highest obesity rate was found for both men and women in Malta, where it was higher than the highest EU average rate for men by $0.3 \mathrm{pp}$. In 2016, the average rate was lower than in 2009, for both men and women ( $25.1 \%$ and $25.3 \%$, respectively), which presumably stems from the changed methodology of presenting results as the 1999-2009 data applied to persons aged $\geq 20$ years, while $2010-2016$ data to persons aged $\geq 18$ years. The addition of younger people, i.e. a group with the lowest percentage of obese persons, to the study group, probably lowered these results globally, but significantly affected the structure in individual countries, Poland included. Therefore, among men, the obesity rate decreased compared to 2009 by $5.3 \mathrm{pp}$, and in the group of women by 3.1 pp; thus, it could be concluded that in Poland there were very few obese young people aged 18-20 years, which reduced the overall rate for the study groups. Obesity growth dynamics in Poland remained greater for men than for women $-2.9 \%$ per year for men vs. $1.7 \%$ per year for women.

Regression equation describing the relationship between the year and the percentage of obese people is as follows:

Percentage $=25.7+0.07^{\star}($ Year -1996$)+0.63^{\star}$ Gender $($ Female $=0$, Male $=1$.

The coefficient for the year is estimated with some accuracy $(b=0.07,95 \%$ CI $[0.06,0.09])$ and is statistically significant $(t(77)=9.20, \mathrm{p}<0.001)$. The linear regression model 
Table 1. Obesity prevalence in men and women aged over 20 in EU countries in 1999-2009 in percentages.

\begin{tabular}{|c|c|c|c|c|c|c|c|c|c|c|c|c|c|c|c|c|c|c|c|c|c|c|c|c|}
\hline \multirow{3}{*}{ EU country } & \multicolumn{24}{|c|}{$\mathrm{BMI} \geq 30$ (crude estimate) } \\
\hline & \multicolumn{2}{|c|}{1999} & \multicolumn{2}{|c|}{2000} & \multicolumn{2}{|c|}{2001} & \multicolumn{2}{|c|}{2002} & \multicolumn{2}{|c|}{2003} & \multicolumn{2}{|c|}{2004} & \multicolumn{2}{|c|}{2005} & \multicolumn{2}{|c|}{2006} & \multicolumn{2}{|c|}{2007} & \multicolumn{2}{|c|}{2008} & \multicolumn{2}{|c|}{2009} & \multicolumn{2}{|c|}{$1999=100^{*}$} \\
\hline & M & $\mathrm{F}$ & M & $\mathrm{F}$ & M & $\mathrm{F}$ & M & $\mathrm{F}$ & $M$ & $\mathrm{~F}$ & M & $\mathrm{F}$ & M & $\mathrm{F}$ & M & $\mathrm{F}$ & M & $\mathrm{F}$ & M & $\mathrm{F}$ & M & $\mathrm{F}$ & M & $\mathrm{F}$ \\
\hline stria & 26.0 & 25.2 & 26.1 & 25.2 & 26.2 & 25.3 & 26.2 & 25.4 & 26.3 & 25.4 & 26.4 & 25.5 & 26.5 & 25.5 & 26.6 & 25.6 & 26.7 & 25.7 & 26.7 & 25.7 & 26.8 & 25.8 & 103.1 & 102.4 \\
\hline lgium & 26.4 & 25.6 & 26.4 & 25.6 & 26.5 & 25.7 & 26.6 & 25.7 & 26.7 & 25.7 & 26.7 & 25.7 & 26.8 & 25.8 & 26.9 & 25.8 & 27.0 & 25.8 & 27.1 & 25.8 & 27.2 & 25.8 & 103.0 & 100.8 \\
\hline ulgaria & 25.9 & 25.7 & 26.0 & 25.7 & 26.0 & 25.7 & 26.1 & 25.7 & 26.2 & 25.8 & 26.3 & 25.8 & 26.4 & 25.9 & 26.5 & 25.9 & 26.6 & 26.0 & 26.7 & 26.1 & 26.8 & 26.1 & 103.5 & 101.6 \\
\hline Cyprus & 26.8 & 25.8 & 26.9 & 25.9 & 27.0 & 26.0 & 27.1 & 26.0 & 27.2 & 26.1 & 27.2 & 26.2 & 27.3 & 26.2 & 27.4 & 26.3 & 27.5 & 26.4 & 27.6 & 26.4 & 27.7 & 26.5 & 103.4 & 102.7 \\
\hline $\begin{array}{l}\text { Czech } \\
\text { Republic }\end{array}$ & 27.4 & 27.0 & 27.5 & 27.0 & 27.6 & 27.0 & 27.7 & 27.1 & 27.8 & 27.1 & 27.9 & 27.1 & 27.9 & 27.2 & 28.1 & 27.2 & 28.2 & 27.3 & 28.3 & 27.3 & 28.4 & 27.3 & 103.6 & 101.1 \\
\hline nmark & .4 & 24.8 & 25.5 & 4.9 & 25,6 & 24.9 & 25.7 & 5.0 & 5.8 & 25.1 & 25.9 & 5.2 & 25.0 & 25.3 & 26.1 & 25.3 & 26.3 & 25.4 & 26.4 & 25.5 & 26.5 & 25.6 & 104.3 & 03.2 \\
\hline tonia & 25.3 & 25.0 & 25.4 & 25.1 & 25.5 & 25.2 & 25.7 & 25.2 & 25.8 & 25.3 & 25.9 & 25.3 & 26.0 & 25.4 & 26.2 & 25.4 & 26.3 & 25.5 & 26.4 & 25.5 & 26.6 & 25.5 & 105.1 & 102.0 \\
\hline Finland & 26.3 & 25.8 & 26.4 & 25.8 & 26.5 & 25.9 & 26.5 & 25.9 & 26.6 & 26.0 & 26.7 & 26.0 & 26.8 & 26.1 & 26.9 & 26.1 & 27.0 & 26.2 & 27.1 & 26.2 & 27.2 & 26.3 & 103.4 & 101.9 \\
\hline France & 25.7 & 25.0 & 25.7 & 25.0 & 25.8 & 25.1 & 25.9 & 25.1 & 26.0 & 25.2 & 26.0 & 25.2 & 26.1 & 25.2 & 26.2 & 25.2 & 26.3 & 25.3 & 26.3 & 25.3 & 26.4 & 25.3 & 102.7 & 101.2 \\
\hline Germany & 26.9 & 26.0 & 27.0 & 26.0 & 27.1 & 26.1 & 27.1 & 26.2 & 27.2 & 26.2 & 27.3 & 26.2 & 27.3 & 26.3 & 27.4 & 26.3 & 27.5 & 26.4 & 27.6 & 26.4 & 27.7 & 26.5 & 103.0 & 101.9 \\
\hline Greece & 25.8 & 25.0 & 25.9 & 25.1 & 25.9 & 25.1 & 26.0 & 25.2 & 26.1 & 25.3 & 26.2 & 25.3 & 26.3 & 25.4 & 26.4 & 25.4 & 26.6 & 25.5 & 26.7 & 25.5 & 26.8 & 25.6 & 103.9 & 102.4 \\
\hline Hungary & 26.4 & 25.9 & 26.5 & 25.9 & 26.6 & 26.0 & 26.7 & 26.1 & 26.8 & 26.2 & 26.9 & 26.3 & 27.0 & 26.3 & 27.1 & 26.4 & 27.2 & 26.5 & 27.4 & 26.6 & 27.5 & 26.6 & 104.2 & 102.7 \\
\hline Ireland & 26.9 & 26.0 & 27.0 & 26.1 & 27.1 & 26,2 & 27.2 & 26.2 & 27.3 & 26.3 & 27.4 & 26.4 & 27.5 & 26.4 & 27.5 & 26.5 & 27.6 & 26.6 & 27.7 & 26.7 & 27.8 & 26.8 & 103.3 & 103.1 \\
\hline Italy & 26.1 & 25.2 & 26.1 & 25.4 & 26.2 & 25.4 & 26.3 & 25.4 & 26.3 & 25.4 & 26.4 & 25.3 & 26.5 & 25.3 & 26.6 & 25.3 & 26.7 & 25.3 & 26.8 & 25.2 & 26.8 & 25.2 & 102.7 & 100.0 \\
\hline Latvia & 25.7 & 25.6 & 25.7 & 25.6 & 25.8 & 25.7 & 25.9 & 25.8 & 26.0 & 25.8 & 26.2 & 25.9 & 26.3 & 26.0 & 26.4 & 26.1 & 26.6 & 26.1 & 26.7 & 26.2 & 26.8 & 26.3 & 104.3 & 102.7 \\
\hline Lithuania & 26.1 & 26.1 & 26.2 & 26.2 & 26.3 & 26.2 & 26.4 & 26.3 & 26.5 & 26.4 & 26.6 & 26.4 & 26.7 & 26.5 & 26.8 & 26.6 & 27.0 & 26.6 & 27.1 & 26.6 & 27.2 & 26.6 & 104.2 & 101.9 \\
\hline Luxembourg & 26.8 & 26.0 & 26.9 & 26.1 & 27.0 & 26.2 & 27.1 & 26.3 & 27.2 & 26.4 & 27.3 & 26.4 & 27.4 & 26.5 & 27.5 & 26.6 & 27.6 & 26.6 & 27.7 & 26.7 & 27.8 & 26.7 & 103.7 & 102.7 \\
\hline Malta & 27.1 & 27.1 & 27.2 & 27.2 & 27.3 & 27.3 & 27.4 & 27.4 & 27.5 & 27.5 & 27.5 & 27.5 & 27.6 & 27.6 & 27.7 & 27.7 & 27.8 & 27.8 & 27.9 & 27.9 & 27.9 & 27.9 & 103.0 & 103.0 \\
\hline Netherlands & 25.4 & 25.2 & 25.5 & 25.3 & 25.6 & 25.4 & 25.7 & 25.4 & 25.8 & 25.5 & 25.9 & 25.6 & 26.0 & 25.7 & 26.1 & 25.8 & 26.3 & 25.9 & 26.4 & 26.0 & 26.5 & 26.1 & 104.3 & 103.6 \\
\hline Poland & 26.0 & 26.0 & 26.1 & 26.0 & 26.2 & 26.1 & 26.2 & 26.1 & 26.3 & 26.1 & 26.4 & 26.2 & 26.5 & 26.2 & 26.6 & 26.3 & 26.7 & 26.3 & 26.8 & 26.4 & 26.9 & 26.4 & 103.5 & 101.5 \\
\hline omania & 24.8 & 25.1 & 24.8 & 25.1 & 24.8 & 25.1 & 24.9 & 25.2 & 25.0 & 25.3 & 25.1 & 25.3 & 25.2 & 25.4 & 25.3 & 25.5 & 25.5 & 25.5 & 25.6 & 25.5 & 25.7 & 25.6 & 103.6 & 102.0 \\
\hline Slovakia & 26.3 & 26.2 & 26.4 & 26.2 & 26.4 & 26.2 & 26.5 & 26.2 & 26.5 & 26.2 & 26.6 & 26.2 & 26.7 & 26.3 & 26.8 & 26.4 & 26.9 & 26.4 & 27.0 & 26.5 & 27.1 & 26.5 & 103.0 & 101.1 \\
\hline Slovenia & 26.7 & 26.4 & 26.8 & 26.5 & 26.9 & 26.6 & 27.0 & 26.6 & 27.1 & 26.7 & 27.2 & 26.7 & 27.3 & 26.7 & 27.4 & 26.8 & 27.5 & 26.8 & 27.6 & 26.8 & 27.7 & 26.9 & 103.7 & 101.9 \\
\hline Spain & 26.6 & 26.3 & 26.8 & 26.3 & 26.9 & 26.4 & 27.0 & 26.5 & 27.1 & 26.5 & 27.3 & 26.6 & 27.4 & 26.7 & 27.5 & 26.7 & 27.6 & 26.8 & 27.8 & 26.9 & 27.9 & 26.9 & 104.9 & 102.3 \\
\hline Sweden & 25.9 & 25.2 & 25.9 & 25.2 & 26.0 & 25.2 & 26.1 & 25.3 & 26.2 & 25.3 & 26.2 & 25.3 & 26.3 & 25.4 & 26.4 & 25.4 & 26.5 & 25.5 & 26.6 & 25.5 & 26.7 & 25.5 & 103.1 & 101.2 \\
\hline 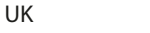 & 26.7 & 26.4 & 26.8 & 26.5 & 26.9 & 26.5 & 27.0 & 26.7 & 27.1 & 26.8 & 27.2 & 26.8 & 27.3 & 26.9 & 27.4 & 26.0 & 27.5 & 26.1 & 27.6 & 26.2 & 27.7 & 26.3 & 103.7 & 99.6 \\
\hline
\end{tabular}

* Single-base index number shows percentage of increase/decrease rate (over or below 100), compared to base year (1999). Lowest and highest indicators are highlighted. Source: own elaboration based on WHO Global InfoBase (www.who.int, retrieved 20.06.2017).

is statistically significant $(\mathrm{F}(2,613)=121.6, \mathrm{p}<0.001)$ and allows the explanation that only $28.2 \%$ of the percentage of obesity variance (R^2_adj $=0.212,90 \% \mathrm{CI}[0.17,0.27])($ Tab. 4$)$.

Regression equations describing the analyzed relationship for worldwide data: Percentage $=25.1+0.45^{\star}($ Year-2010); 25.1 is the average value for the world (Tab. 5). The linear regression model is statistically significant $(\mathrm{F}(7,116)=28.5, \mathrm{p}<0.001)$ and explains $61 \%$ of the variance of the variable percentage of obese people (R2_adj $=0.61,90 \% \mathrm{CI}=[0.49,0.68])$.

Analysis of obesity epidemic dynamics in all EU countries shows the slowest increase in obesity rate growth for obese men and for obese women in Malta, while the fastest for men in Portugal and for women in Ireland. Considering Europe as an entire region of the world, the growth of this phenomenon is faster among men than women, although there are more obese women than men (in 2016 by $0.2 \mathrm{pp}$ ).

With the growth rate remaining at the estimated level in individual EU countries, the percentage of obese people in Poland may currently amount to $26.9 \%$ for men and $26.6 \%$ for women, and in Europe as a region-26.5\% for men and $26.1 \%$ for women.
In 2020 , the obesity prevalence in Poland may be as high as $28.5 \%$ and $27.6 \%$, respectively, and in Europe $-28.0 \%$ and $27.1 \%$. In 2030, there will probably be more obese men (38.1\%) than women $(32.7 \%)$ in Poland, and in Europe likewise $36.6 \%$ and $32.0 \%$, respectively. Globally meanwhile, obesity may affect almost one in 5 men (18.9\%) and almost one in 4 women $(22.5 \%)$ worldwide. In order to assess the global trends concerning obesity, the analyzed rates for European countries were compared to data for other world regions (Tab. 3).

Of the analyzed non-European countries, the greatest number of obese men in 2016 was noted in the USA, Kuwait, and Canada, and of obese women in Kuwait, Saudi Arabia, and United Arab Emirates. and the share of obese persons, particularly among women, was significantly higher than the EU average. At the same time, the issue of obesity in these regions is characterized by a relatively slow growth rate.

The lowest number of obese people were noted for male populations of Uganda, Bangladesh, Nepal, and India (below $3 \%$ ), and for the female populations - below 5\% in Japan, Bangladesh, Nepal, and India. 
Table 2. Obesity prevalence among people aged over 18 in EU countries in 2010-2016 in percentages, and change dynamics analysis with forecast for the next few years

\begin{tabular}{|c|c|c|c|c|c|c|c|c|c|c|}
\hline \multirow{2}{*}{ EU country } & \multicolumn{5}{|c|}{ Male } & \multicolumn{5}{|c|}{ Female } \\
\hline & 2010 & 2016 & $2010=100^{*}$ & 2020 & 2030 & 2010 & 2016 & $2010=100^{*}$ & 2020 & 2030 \\
\hline Austria & 20.1 & 23.4 & 116.4 & 26.1 & 34.1 & 18.3 & 20.6 & 112.6 & 22.4 & 27.5 \\
\hline Belgium & 22.1 & 25.1 & 113.6 & 27.4 & 34.3 & 22.2 & 23.9 & 107.7 & 25.3 & 28.8 \\
\hline Bulgaria & 23.5 & 27.5 & 117.0 & 30.8 & 40.7 & 25.0 & 27.4 & 109.6 & 29.3 & 34.4 \\
\hline Croatia & 22.1 & 26.0 & 117.6 & 29.2 & 39.0 & 25.4 & 28.2 & 111.0 & 30.4 & 36.5 \\
\hline Czech Republic & 25.0 & 28.5 & 114.0 & 31.3 & 39.4 & 26.6 & 28.6 & 107.5 & 30.3 & 34.3 \\
\hline Denmark & 20.7 & 23.7 & 114.5 & 26.1 & 33.1 & 17.4 & 18.9 & 108.6 & 20.1 & 23.2 \\
\hline Estonia & 18.9 & 21.9 & 115.9 & 24.3 & 31.6 & 23.9 & 25.3 & 105.9 & 26.6 & 29.3 \\
\hline Finland & 22.7 & 25.7 & 113.2 & 28.0 & 34.9 & 22.2 & 24.2 & 109.0 & 25.8 & 30.0 \\
\hline France & 20.5 & 23.5 & 114.6 & 25.9 & 32.9 & 21.2 & 23.0 & 108.5 & 24.5 & 28.2 \\
\hline Greece & 22.2 & 26.0 & 117.1 & 29.1 & 38.5 & 26.4 & 28.7 & 108.7 & 30.6 & 35.3 \\
\hline Hungary & 25.7 & 29.9 & 116.3 & 33.3 & 43.6 & 25.0 & 27.5 & 110.0 & 29.5 & 34.8 \\
\hline Ireland & 22.0 & 26.5 & 120.5 & 30.3 & 42.4 & 22.9 & 27.3 & 119.2 & 30.6 & 42.0 \\
\hline Italy & 19.7 & 22.5 & 114.2 & 24.7 & 31.2 & 21.4 & 23.3 & 108.9 & 24.9 & 28.8 \\
\hline Latvia & 19.8 & 22.9 & 115.7 & 25.4 & 32.8 & 26.5 & 28.0 & 105.7 & 29.4 & 32.3 \\
\hline Lithuania & 22.0 & 25.3 & 115.0 & 27.9 & 35.7 & 29.1 & 30.9 & 106.2 & 32.5 & 36.0 \\
\hline Luxembourg & 22.6 & 26.0 & 115.0 & 28.7 & 36.8 & 20.4 & 22.4 & 109.8 & 24.0 & 28.2 \\
\hline Malta & 27.7 & 30.9 & 111.6 & 33.3 & 40.4 & 29.7 & 31.2 & 105.1 & 32.7 & 35.5 \\
\hline Netherlands & 19.1 & 22.7 & 118.8 & 25.7 & 35.0 & 20.8 & 23.4 & 112.5 & 25.4 & 31.2 \\
\hline Poland & 21.6 & 25.4 & 117.6 & 28.5 & 38.1 & 23.3 & 25.7 & 110.3 & 27.6 & 32.7 \\
\hline Portugal & 18.2 & 22.1 & 121.4 & 25.4 & 36.1 & 21.4 & 24.2 & 113.1 & 26.4 & 32.7 \\
\hline Romania & 20.6 & 24.9 & 120.9 & 28.6 & 40.2 & 21.4 & 24.2 & 113.1 & 26.4 & 32.7 \\
\hline Slovenia & 18.2 & 21.4 & 117.6 & 24.0 & 32.1 & 21.4 & 23.6 & 110.3 & 25.4 & 30.0 \\
\hline Spain & 23.3 & 27.1 & 116.3 & 30.2 & 39.4 & 24.7 & 27.2 & 110.1 & 29.2 & 34.5 \\
\hline Sweden & 20.9 & 24.2 & 115.8 & 26.8 & 34.8 & 18.2 & 20.0 & 109.9 & 21.4 & 25.3 \\
\hline UK & 24.4 & 28.6 & 117.2 & 32.0 & 42.5 & 26.9 & 30.4 & 113.0 & 33.1 & 41.0 \\
\hline Europe overall & 21.6 & 25.1 & 116.3 & 28.0 & 36.6 & 23.0 & 25.3 & 109.9 & 27.1 & 32.0 \\
\hline
\end{tabular}

* Single-base index number shows percentage of increase/decrease rate (over or below 100), compared to base year (2010). Lowest and highest indicators were highlighted.

Source: own elaboration based on the WHO Global InfoBase (www.who.int, retrieved 10.06.2018).

People affected with overweight were the fewest in SouthEast Asia. However, it must be noted that in this region, as well as in the Western Pacific region, the percentage of obese people is growing the fastest, at the rate of $6 \%$ per year. In this region, the growth rate is the highest in Thailand for men (10.5\% per year), while for women in Bangladesh this rate is $8.1 \%$ per year. In the Western Pacific region, on the other hand, the highest growth rate of obesity prevalence is recorded for both men and women in China $(9.2 \%$ and $6.5 \%$, respectively).

Compared to Europe, these rates are at least 5.3 pp higher for men and $4.2 \mathrm{pp}$ higher for women. Global analysis of the situation shows that the issue of obesity is becoming more severe worldwide, with various - slower or faster - growth rates in individual world regions, but there is a clear upward trend everywhere. The rate of changes in Europe compared to other world regions may be considered low, because for women it is the lowest of all world regions (110.6), and for men, Europe is outranked only by North and South America (115.4; Europe 118.2). However, from 2010, each year 0.5\% more of people with BMI>30 have been observed. Because of the $25.1 \%$ of obese people, Europe is no longer different from both Americas and the Mediterranean countries, although it has significantly more obese people than Africa (by 14.7\%), Pacific Region (by 14.6\%) and SE Asia (by 19\%). Worldwide, there are 5.5\% less obese men than women e (Tab. 5; Fig. 2).

Based on the presented data concerning obesity prevalence, a forecast analysis for EU Countries, Europe and other world regions has been performed (Tables 2, 3; Fig. 3).

To assess the annual growth rate, results for all countries were aligned by deducting the value for 1999 for females and males separately. Regression analysis with $1^{\text {st }}$ order autocorrelation covariant was performed for these data. Correlation coefficient for the results was $\mathrm{phi}=.23$ and regression equation parameters are as follows: Percentage $=0.072^{*}$ year $($ from 1999, $\mathrm{SE}=.002)+0.087$ * Males $(\mathrm{SE}=.016)-0.098^{\star}$ Females $(\mathrm{SE}=.016)+$ Baseline percentage for the country in 1999. Autocorrelation analysis failed to show any interpretable regularities $(\mathrm{RSE}=.153, \mathrm{Md}$ resid $=.055$ ). 
Table 3. Obesity prevalence in men and women aged over 18, selected worldwide in countries by geographical region in 2010-2016, in percentages and change dynamics analysis with a forecast for the next few years, BMI $\geq 30$ (crude estimate)

\begin{tabular}{|c|c|c|c|c|c|c|c|c|c|c|}
\hline \multirow{2}{*}{ Country/Region of the World } & \multicolumn{5}{|c|}{ Men } & \multicolumn{5}{|c|}{ Women } \\
\hline & 2010 & 2016 & $2010=100^{*}$ & 2020 & 2030 & 2010 & 2016 & $2010=100^{*}$ & 2020 & 2030 \\
\hline Africa, including: & 3.6 & 4.8 & 133.3 & 5.96 & 10.24 & 11.0 & 13.2 & 120.0 & 15.05 & 20.88 \\
\hline Zambia & 2.2 & 3.0 & 136.4 & 3.80 & 6.84 & 7.7 & 10.0 & 129.9 & 12.15 & 19.75 \\
\hline Democratic Republic of the Congo & 2.2 & 3.1 & 140.9 & 4.04 & 7.81 & 6.2 & 8.0 & 129.0 & 9.66 & 15.50 \\
\hline Nigeria & 2.8 & 4.1 & 146.4 & 5.52 & 11.64 & 8.8 & 11.5 & 130.7 & 14.04 & 23.11 \\
\hline Republic of South Africa & 10.9 & 14.5 & 133.0 & 17.96 & 30.68 & 34.6 & 38.5 & 111.3 & 41.48 & 49.97 \\
\hline Uganda & 1.0 & 1.5 & 150.0 & 2.07 & 4.60 & 5.0 & 6.8 & 136.0 & 8.58 & 15.38 \\
\hline Americas, including: & 22.7 & 26.2 & 115.4 & 28.99 & 37.38 & 28.2 & 31.7 & 112.4 & 34.41 & 42.23 \\
\hline Brazil & 15.1 & 18.5 & 122.5 & 21.44 & 30.97 & 22.2 & 25.9 & 116.7 & 28.90 & 38.02 \\
\hline USA & 32.2 & 36.5 & 113.4 & 39.87 & 49.70 & 34.5 & 38.2 & 110.7 & 41.01 & 48.97 \\
\hline Canada & 27.3 & 31.2 & 114.3 & 34.28 & 43.37 & 27.9 & 31.5 & 112.9 & 34.30 & 42.43 \\
\hline Argentina & 23.8 & 27.4 & 115.1 & 30.27 & 38.82 & 26.6 & 29.6 & 111.3 & 31.89 & 38.42 \\
\hline Mexico & 20.3 & 23.7 & 116.7 & 26.46 & 34.84 & 28.9 & 32.6 & 112.8 & 35.47 & 43.79 \\
\hline South-East Asia, including: & 2.1 & 3.2 & 152.4 & 4.47 & 10.33 & 4.4 & 6.0 & 136.4 & 7.59 & 13.67 \\
\hline Bangladesh & 1.4 & 2.2 & 157.1 & 3.17 & 7.86 & 3.1 & 4.6 & 148.4 & 6.27 & 13.62 \\
\hline India & 1.8 & 2.7 & 150.0 & 3.72 & 8.28 & 3.6 & 4.9 & 136.1 & 6.19 & 11.11 \\
\hline Indonesia & 3.1 & 4.9 & 158.1 & 6.73 & 19.12 & 6.5 & 9.0 & 138.5 & 12.41 & 26.92 \\
\hline Nepal & 1.7 & 2.5 & 147.1 & 2.07 & 2.87 & 3.5 & 4.8 & 137.1 & 5.54 & 9.16 \\
\hline Thailand & 4.6 & 7.5 & 163.0 & 10.61 & 26.67 & 9.9 & 13.8 & 139.4 & 17.35 & 31.63 \\
\hline Eastern Mediterranean, including: & 11.7 & 14.9 & 127.4 & 17.81 & 27.82 & 20.7 & 24.3 & 117.4 & 27.24 & 36.26 \\
\hline Egypt & 17.7 & 22.0 & 124.3 & 24.60 & 36.56 & 35.2 & 40.0 & 113.6 & 41.41 & 52.29 \\
\hline United Arab Emirates & 19.5 & 26.7 & 136.9 & 34.06 & 44.29 & 31.0 & 38.8 & 125.2 & 42.44 & 69.40 \\
\hline Pakistan & 3.8 & 5.5 & 144.7 & 8.40 & 13.20 & 7.6 & 10.1 & 132.9 & 8.40 & 13.20 \\
\hline Kuwait & 28.8 & 33.0 & 114.6 & 34.89 & 40.10 & 40.5 & 43.9 & 108.4 & 46.53 & 51.04 \\
\hline Saudi Arabia & 25.9 & 31.0 & 119.7 & 33.43 & 44.93 & 35.9 & 41.2 & 114.8 & 44.85 & 52.72 \\
\hline Western Pacific, including: & 4.2 & 6.3 & 150.0 & 8.68 & 19.31 & 5.3 & 7.2 & 135.8 & 9.08 & 16.21 \\
\hline Australia & 26.7 & 30.7 & 114.9 & 33.86 & 43.26 & 26.8 & 30.1 & 112.3 & 32.65 & 39.99 \\
\hline Japan & 3.4 & 4.6 & 135.3 & 5.78 & 10.24 & 3.6 & 4.1 & 113.9 & 4.49 & 5.65 \\
\hline Republic of Korea & 3.7 & 4.6 & 124.3 & 5.39 & 8.02 & 4.6 & 5.3 & 115.2 & 5.86 & 7.52 \\
\hline Singapore & 5.2 & 6.2 & 119.2 & 7.03 & 9.64 & 6.4 & 7.0 & 109.4 & 7.45 & 8.71 \\
\hline China & 4.0 & 6.2 & 155.0 & 8.81 & 21.18 & 5.1 & 7.1 & 139.2 & 9.14 & 17.21 \\
\hline Europe & 19.8 & 23.4 & 118.2 & 26.37 & 35.54 & 24.5 & 27.1 & 110.6 & 29.07 & 34.65 \\
\hline Global & 9.0 & 11.1 & 123.3 & 12.93 & 18.94 & 13.1 & 15.3 & 116.8 & 17.09 & 22.52 \\
\hline
\end{tabular}

Source: Own elaboration based on the WHO Global InfoBase (www.who.int, retrierved 10.06.2018).

WHO method of estimation: Worldwide trends in body-mass index, underweight, overweight, and obesity 1975 - 2016: pooled analysis of 2,416 population-based measurement studies with 128.9 million participants. Lancet 2017. DOI: http://dx.doi.org/10.1016/S0140-6736(17)32129-3.

* Single-base index number shows percentage of increase/decrease rate (over or below 100), compared to base year (2010). Highest single-base indexes highlighted. Percentages indicators over $30 \%$ for 2020 forecast and over $40 \%$ for 2030 are highlighted.

Table 4. Linear regression analysis for changes in obese percentages according to year among men and women in EU countries

\begin{tabular}{lcccc}
\hline Predictor & $\mathrm{b}$ & $95 \% \mathrm{Cl}$ & $\mathrm{t}(613)$ & $\mathrm{p}$ \\
\hline Year & 0.07 & {$[0.07-0.08]$} & 37.17 & $<0.001$ \\
\hline Women & -0.10 & {$[-0.12-0.07]$} & -7.32 & $<0.001$ \\
\hline Men & 0.08 & {$[0.06-0.11]$} & 6.45 & $<0.001$ \\
\hline
\end{tabular}

With the growth rate remaining at the estimated level, the percentage of obese people above $30 \%$ ( 1 in 3 people) may be achieved in 2020 among the male populations of Bulgaria, the Czech Republic, Ireland, Spain, and the UK, and up to $33.3 \%$ in Hungary and Malta. For women, it would be attained in Croatia, the Czech Republic, Greece, Ireland,
Table 5. Linear regression analysis for changes in obese percentages according to year in men compared to women in regions, according to WHO classification

\begin{tabular}{lcccc}
\hline Predictor & $\mathrm{b}$ & $98 \% \mathrm{Cl}$ & $\mathrm{t}(116)$ & $\mathrm{P}$ \\
\hline Intercept & 25.11 & {$[17.14 .33 .07]$} & 6.24 & $<0.001$ \\
\hline Year & 0.45 & {$[-0.02 .0 .91]$} & 1.92 & 0.058 \\
\hline Gender: Male & -5.50 & {$[-8.27 .-2.72]$} & -3.92 & $<0.001$ \\
\hline Region: Africa & -14.74 & {$[-23.08 .-6.40]$} & -3.50 & 0.001 \\
\hline Region: Americas & 3.91 & {$[-4.43 .12 .25]$} & 0.93 & 0.355 \\
\hline Region: E. Mediterranean & 1.70 & {$[-6.64 .10 .05]$} & 0.40 & 0.686 \\
\hline Region: SE Asia & -19.04 & {$[-27.38 .-10.70]$} & -4.52 & $<0.001$ \\
\hline Region: W Pacific & -14.60 & {$[-22.94 .-6.26]$} & -3.47 & 0.001
\end{tabular}




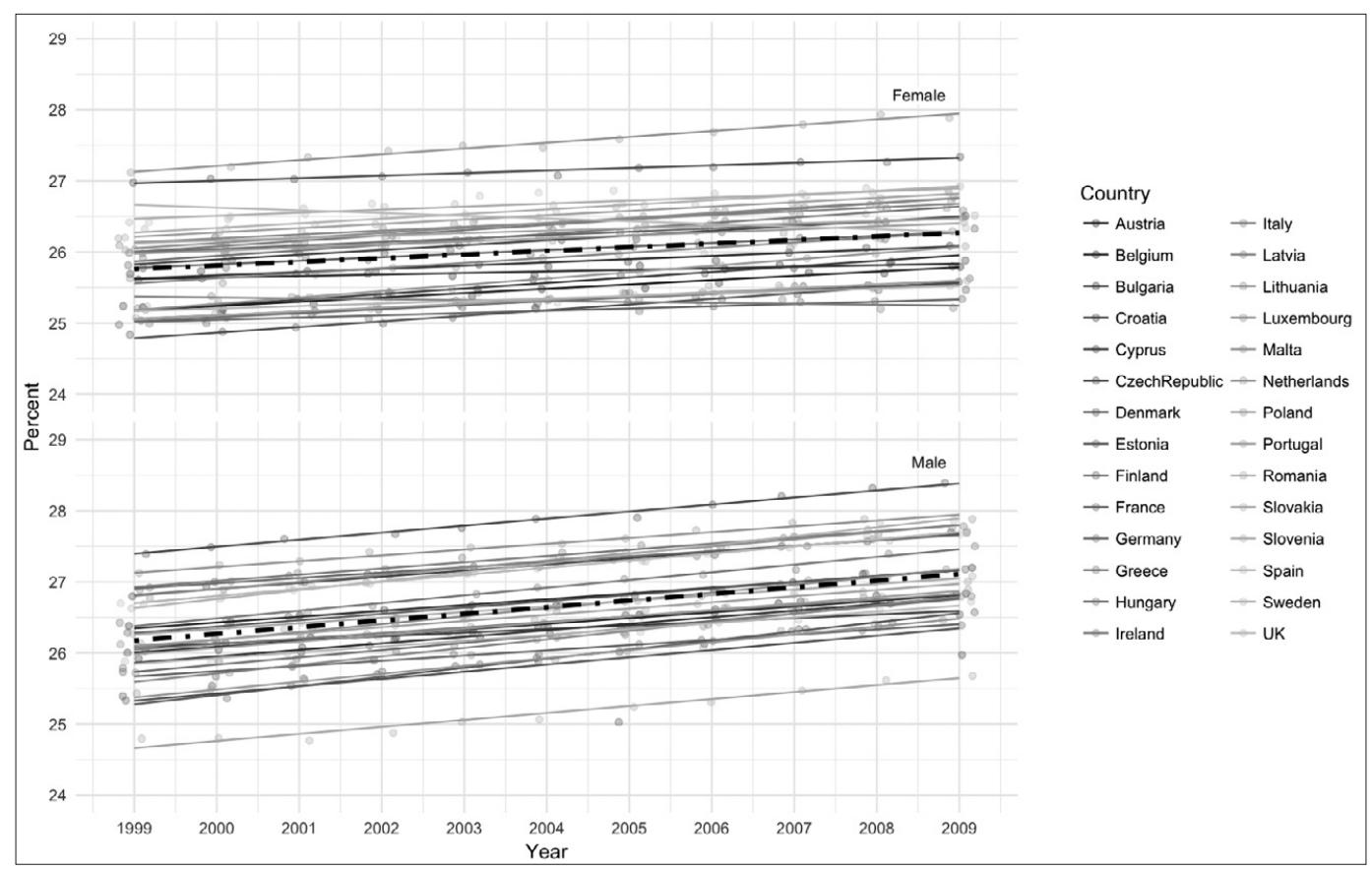

Figure 1. Trends in obesity prevalence among men and woman in EU countries.

Source: Own elaboration based on data presented in Table 1.

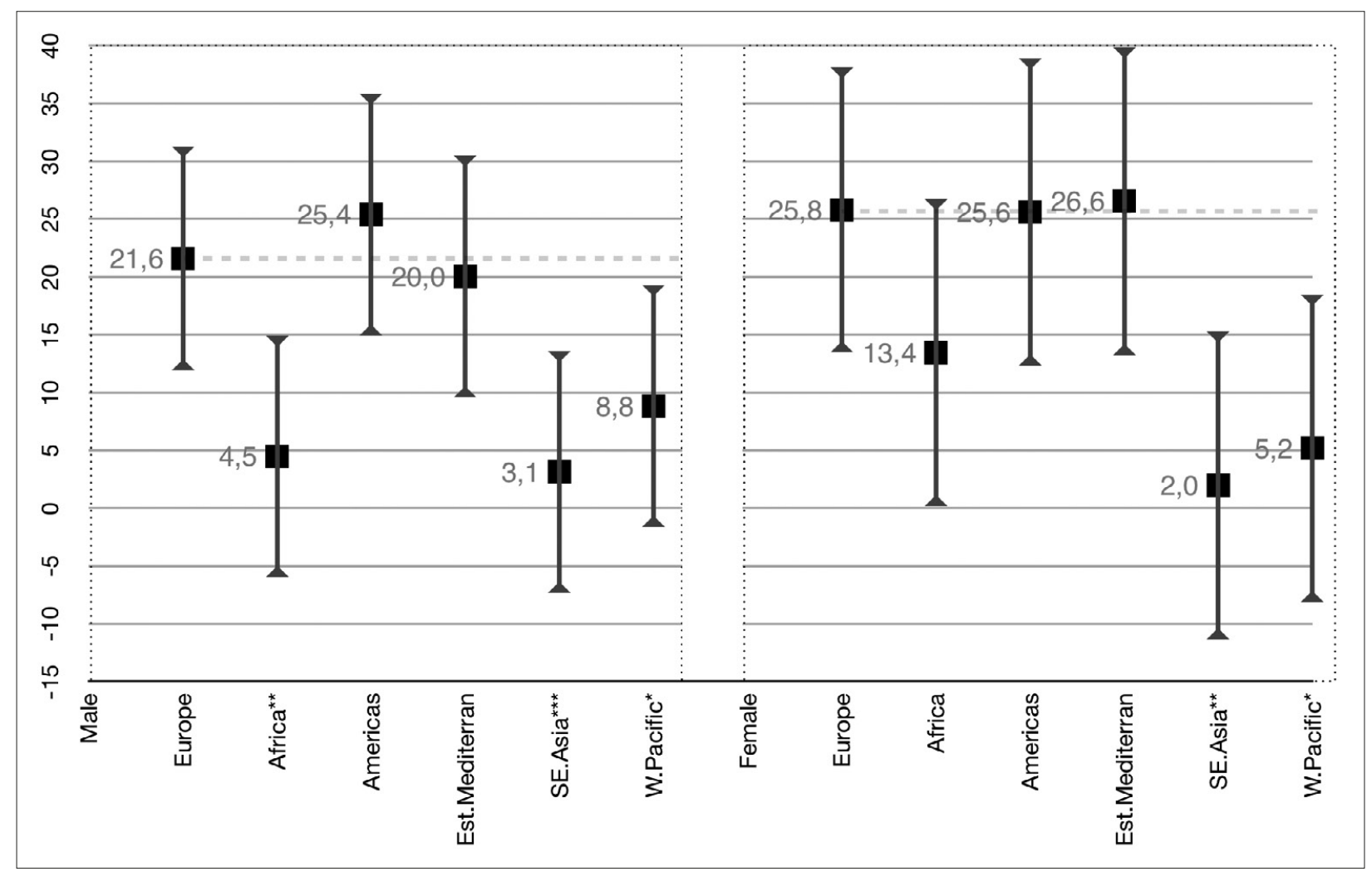

Figure 2. Overall mean values in individual regions with $95 \%$ confidence interval. * regions which statistically significantly differ from Europe. Source: Own elaboration based on data presented in Table 3.

Lithuania, and Malta, reaching up to $33.1 \%$ in the UK, that is in 7 of the $28 \mathrm{EU}$ countries. In 2030, these values will exceed $40 \%$ (nearly 1 in 2 people) for men in 6 countries: Bulgaria, Ireland, Malta, Romania, and the UK, reaching up to $43.6 \%$ in Hungary; and for women, in 2 countries: the UK and Ireland reaching up to $42.0 \%$.

Worldwide in 2020, the percentage of obese men above
$30 \%$ will be found in Canada, Argentina, Kuwait, Saudi Arabia, United Arab Emirates and Australia, and reaching $39.9 \%$ in the USA. Among women, it will be above $30 \%$ in Canada, Argentina, Mexico, and Australia, and will exceed $40 \%$ in South Africa, the USA, Egypt, Kuwait, Saudi Arabia, and the United Arab Emirates. In 2030, the percentage of obese men above $40 \%$ will be exceeded in Canada, Kuwait, 


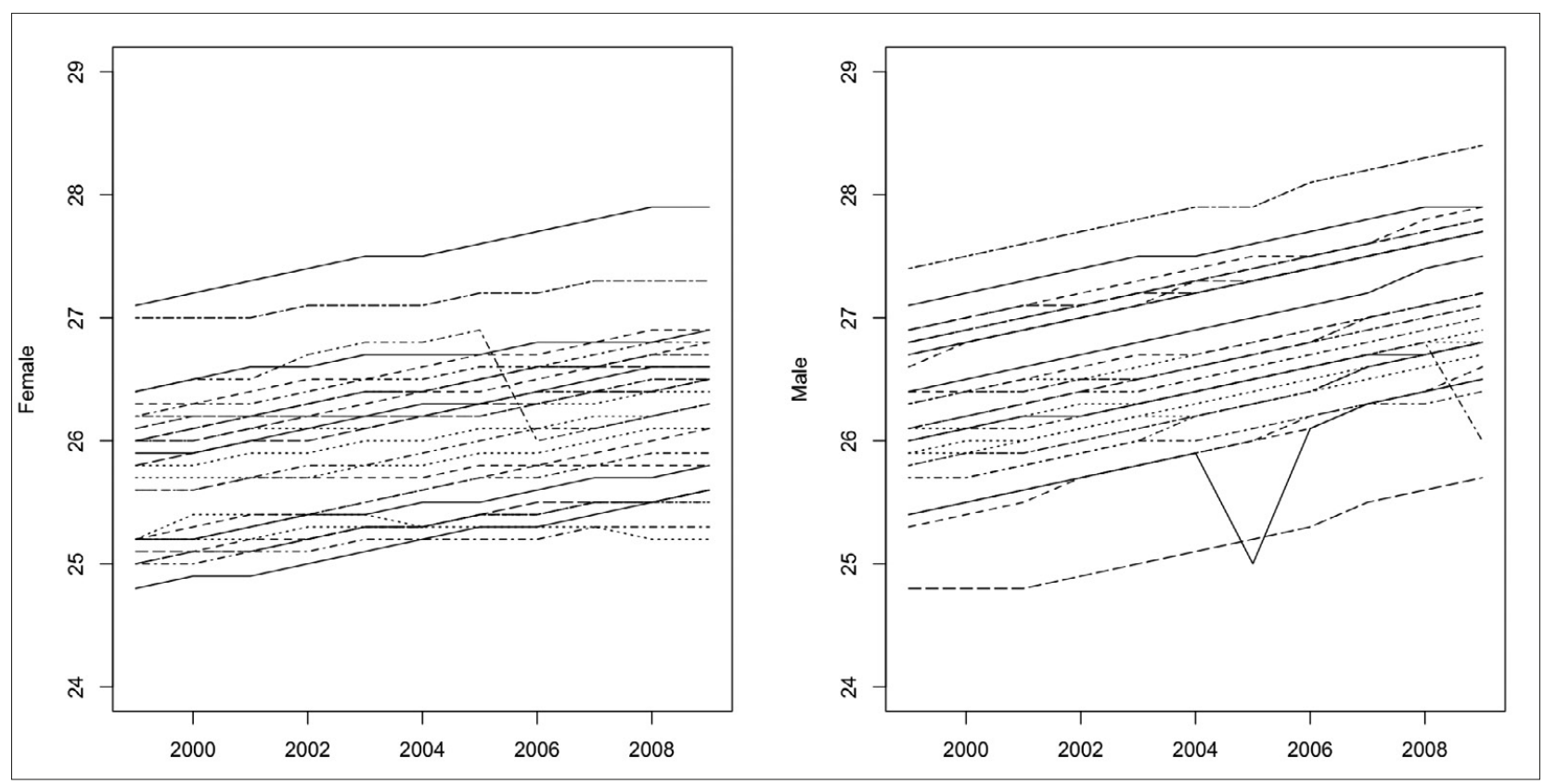

Figure 3. Trends in obesity prevalence among men and women in EU countries The own elaboration based on the data presented in Table 2.

Saudi Arabia, United Arab Emirates, Australia, and the USA (49.7\%). Among women, it will be above $40 \%$ in the USA, Canada, Mexico, and South Africa, and will exceed 50\% in Egypt, Kuwait and Saudi Arabia, with the highest prevalence forecast for the United Arab Emirates at 69.4\%.

\section{DISCUSSION}

There are few countries in the world that do not have eatingrelated problems. In the EU, the food situation is exceedingly good. The decrease in 18 countries, or rather, the stabilization of food production in the EU is certainly a desired effect of the commitment to reduce food surpluses, making the production more green, placing more importance on environmental protection, as well as of market organization, opening possibilities for rapid production compensation in the case of natural disasters or crop failures [14]. In 2013, a relatively new phenomenon related to malnutrition, i.e. overweight and obesity, according to the FAO [15] was present in 73 countries worldwide, 58 of which were in Europe. The presented results clearly indicate that one in 4 Europeans suffers from obesity and - as shown in the forecast analysis - the problem is bound to become more severe. This corroborates the conclusions by James [16] and Blanca et al. [13] who claimed that the obesity prevalence in Europe was $10-25 \%$ for men and 10-30\% of women. Differences between countries are small. In 2013, European countries made up two-thirds of the world's countries with obesity [17]. EU countries, meanwhile, made up as much as $83.3 \%$ of all European countries coping with the problem and more than a half (55.6\%) of world's countries [17]. It can be concluded, that Europe, and the European Union specifically, are regions of abundance and satisfaction, which frequently leads to health problems for its population and losses for its economy. The changes taking place may be seen as consequences of social and economic changes, the effect of progressing urbanization, modernization, and globalization, also on food markets, and intense development of the services sector, technical and technological development, and primarily changes in socio-economic status. The rapid growth of less affluent EU countries, Slovakia, Bulgaria, Romania, Hungary, Croatia, Lithuania, Estonia, Latvia, and Poland, contributes to a surge of obesity prevalence, particularly among men. The nutrition level of the population in these countries, evaluated according to the degree of satisfaction of daily energy requirements, improved. Compared to 1990-1992, the nutritional situation improved the most in Lithuania, Romania, and Estonia; however, the situation at the household level was somewhat different. It must be stressed that as many as $20 \%$ of households in the 'new' EU Member States had difficulties in providing balanced meals to all family members, compared to less than 6\% in the 'old' EU Member States [17]. Daily full-value meals were the most unavailable to households in Bulgaria (43.2\% of all households), Hungary (27.6\%), Latvia (26.8\%), Lithuania (23.2\%), Slovakia (23.0\%), and Romania (21.3\%) [17]. Overconsumption of energy found (FAO, 2013) amounting to at least $142 \%$ of the minimum daily energy requirement established in 2006-2008 in these countries is frequently associated with a low-quality diet promoting overweight and obesity.

As early as 2008, Berghöfer et al. [18] noted that Central and Eastern European countries had higher obesity rates than in Western or Northern Europe. This was mainly associated with greater difficulties in providing a steady access to food quantities sufficient for an active and healthy lifestyle, arising from lower economic growth levels in these countries compared to highly developed countries with higher per capita incomes. In 2012, Dinsa et al. [19] showed in their systemic review that within low-income countries, obesity is more prevalent among the higher-SES groups than in the lower-SES, and the pattern of socio-economic inequalities in obesity is far more mixed in middle-income countries, particularly among men. Only in Romania, obesity is less prevalent among men, as noted also by Jarosz et al. [20]; this country, however, also has a high growth rate of 
the analyzed prevalence in the study group. People with low income usually have limited access to sports facilities or fitness clubs, and the areas they live in rarely promote physical activity. In Poland, however, major changes are observed in this respect, particularly in large cities where there are more and more outdoor gyms, bike paths and playgrounds promoting physical activity.

Lower income, however, significantly affects the choice of diet. A reasonable diet, such as eating fruit instead of high-energy and high-sugar products, is several times more expensive in the great majority of EU countries. In France, for instance, a portion of fruit and vegetables providing $100 \mathrm{kcal}$ has approximately a 5 times higher nutritional value than another food with equivalent energy content, but it is also 5 times more expensive [5].

The greatest number of obese people, however, live in highly developed countries with a higher per capita incomeAustria, Ireland, Luxemburg and the UK. It should be added that these countries also have the highest surplus of energy consumed over energy required, much above the minimum requirement (by 193\%, 184\%, 185\%, 178\%, respectively), and an over-average consumption of protein and fats in the EU scale [17]. In 2006-2008, the minimum daily energy requirement in $\mathrm{EU}$ countries - as established by $\mathrm{FAO}$ - was between 1,910 kcal/person in Malta to 2,000 kcal/person in the Netherlands [17]. In 1961, the daily calorie intake per person in Europe was 2,300. In 1998, it grew to 2,800 [5], and in 2006-2008, the daily energy intake in EU countries was $3,460 \mathrm{kcal}$ per capita and was nearly $1 / 4$ higher than the global average and $2 / 3$ higher than in the least developed countries [17]. In 2006-2008, the daily protein intake in the EU was nearly $1 / 4$ higher and fat intake over $80 \%$ higher than the global average, and nearly 20 times higher and 4 times higher (for protein and fats, respectively) than in countries at a lower level economic development [17]. Consumption of white sugar is also steadily increasing. In early 20 th century, annual consumption in Europe was approximately $5 \mathrm{~kg}$ per person while current statistics show that an average Pole consumes about $42 \mathrm{~kg}$ of white sugar per year, an average German - $35 \mathrm{~kg}$, Frenchman - $36 \mathrm{~kg}$, and Greek - $30 \mathrm{~kg}$, whereas the European average is between $40-60 \mathrm{~kg}$ [21]. Excessive sugar consumption may cause not only tooth caries, but also obesity, diabetes and increased triglyceride concentration [22]. In 2003, the WHO announced that sugarsweetened beverages increase the risk of overweight [23], and the over-consumption of energy, of principal nutrients and simple sugars, made obesity a major problem in terms of nutrition, public health, and population health in the countries of the EU.

Changes are also taking place in terms of differences between genders in highly developed countries with high per capita income, as confirmed by Dinsa et al. [19] this fact deserves attention. These countries have a lower obesity prevalence among women than men while in the other countries women significantly outnumber men in terms of obesity, which leads to the conclusion that obesity affects more women than men. This cannot be concluded unequivocally due to large discrepancies between various countries. Especially because the International Obesity Task Force (IOTF) also reports that in 14 of 36 countries or regions for which data for both genders is available, obesity was more prevalent in men than women while overweight was more prevalent in men in all 36 countries. The largest increase in the percentage of obese women was observed in the Netherlands - by $0.9 \mathrm{pp}$. Considering the significantly larger dynamics of obesity epidemics among men than women, it may be assumed that during the next 10 years these rates will become equal for both genders.

The growing obesity epidemic is fueled by factors associated with the progress of civilization: reduced spending of energy during occupational work and household chores, sedentary lifestyle, new technologies in food processing (reducing the time and physical effort of various household chores), driving cars even for short distances (e.g., to the nearest shop), increasingly common use of high-fructose corn syrup in the food industry, buying highly processed foods; and - most importantly - significant changes in eating habits, such as eating increasingly large meals, significantly exceeding the recommended daily intake of energy, protein, and fats, giving up a diet rich in complex carbohydrates (grains, potatoes), fruit, vegetables and fish for a diet rich in simple sugars (confectionery, sweet drinks), animal fats and vegetable oils, highly processed foods and fast foods [24].

However, analysis of the situation in individual regions of the world shows that the largest number of obese people, both men and women, are currently living in South and North America and the Middle East. The most frequently listed factors contributing to these high obesity rates include: socio-economic factors - increases in GDP per capita reflect improvements in the prosperity of the nation, and directly relate to an improved individual socio-economic status (SES). Therefore, the direct function of GDP per capita has additionally been highlighted as the main underlying factor for the observed positive association between GDP per capita and obesity levels [19,25-28], significant reduction of physical activity resulting from technological development and from lifestyle (extensive road networks, increased availability of cars, greater use of mechanized appliances, widespread use of computers, televisions, and electronic gaming devices, have encouraged a more sedentary lifestyle) [27], traditional/cultural restrictions in women's lifestyle (South Africa, Gulf countries) [29], a more westernized diet - eating highly processed, ready meals with high calorific content, drinking large amounts of sweetened beverages [30], and widespread use of high-fructose corn syrup in the food industry [31, 32].

In turn, South-East Asia and the Western Pacific region with lowest number of obese people are characterized by the highest growth rate. In India, eating habits changed rapidly during the 'Green Revolution' [33] when the availability of absorbable carbohydrates (wheat starch) improved over a short time and fat consumption increased [34]. This was followed by an increased prevalence of obesity. Asian countries are affected by the same risk factors as Caucasian populations, and the distribution of these factors depends on lifestyle, particularly on eating habits which vary between countries [34], and is less marked in Japan than in India or China. In spite of the growing consumption of western foods, the Japanese still eat a lot of foods which prevent atherosclerosis, which is the reason for the longevity of the Japanese population [34]. 


\section{CONCLUSIONS}

Obesity has become a major epidemiological problem and an undisputable health problem in European countries and worldwide, and forecasts for the future are very disturbing. In terms of population health and public health, preventive measures are necessary, such as individual treatment strategies and population-wide measures aimed at preventing the development of obesity.

\section{REFERENCES}

1. Kontis V, Bennett JE, Mathers CD, Li G, Foreman K, Ezzati M. Future life expectancy in 35 industrialised countries: projections with a Bayesian model ensemble. Lancet. 2017; 389(10076): 1323-1335.

2. World Health Organization. Obesity: Preventing and managing the global epidemic. Report of a WHO consultation. Geneva: WHO Technical Report Series 894; 2000: 1-253.

3. Vandevijvere S, Chow CC, Hall KD, Umali E, Swinburn BA. Increased food energy supply as a major driver of the obesity epidemic: a global analysis. Bull World Health Organ. 2015; 93(7): 446-456.

4. Tsigos C, Hainer V, Basdevant A, Finer N, Fried M, Mathus-Vliegen E, et al. Obesity Management Task Force of the European Association for the Study of Obesity. Management of obesity in adults: European clinical practice guidelines. Obes Facts. 2008; 1(2): 106-116.

5. World Health Organization. Geneva: The Organization; 2017 http:// www.euro.who.int/en/health-topics/noncommunicable-diseases/ obesity/data-and-statistics (access: 2017.06.10).

6. Calle EE, Rodriguez C, Walker-Thurmond K, Thun MJ. Overweight, obesity, and mortality from cancer in a prospectively studied cohort of U.S. adults. N Engl J Med. 2003; 348(17): 1625-1638.

7. Adams KF, Schatzkin A, Harris TB, Kipnis V, Mouw T, Ballard-Barbash $\mathrm{R}$, et al. Overweight, obesity and mortality in a large prospective cohort of persons 50 to 71 years old. N Engl J Med. 2006; 355(8): 763-778.

8. Flegal KM, Graubard BI, Williamson DF, Gail MH. Cause-specific excess death associated with underweight, overweight and obesity. JAMA. 2007; 298(17): 2028-2037.

9. Renehan AG, Tyson M, Egger M, Heller RF, Zwahlen M. Body-mass index and incidence of cancer: a systematic review and meta-analysis of prospective observational studies. Lancet. 2008; 371(9612): 569-578.

10. Stevens J, Cai J, Evenson KR, Thomas R. Fitness and fatness as predictors of mortality from all causes and from cardiovascular disease in men and women in the Lipid Research Clinics Study. Am J Epidemiol. 2002; 156(9): 832-841.

11. Roberts RE, Deleger S, Strawbridge WJ, Kaplan GA. Prospective association between obesity and depression: evidence from the Alameda County Study. Int J Obes Relat Metab Disord. 2003; 27(4): 514-521.

12. Linde JA, Jeffery RW, Levy RL, Sherwood NE, Utter J, Pronk NP, et al. Binge eating disorder, weight control self-efficacy, and depression in overweight men and women. Int J Obes Relat Metab Disord. 2004; 28(3): 418-425.

13. Branca F, Nikogosian H, Lobstein T, editors. The challenge of obesity in the WHO European region and the strategies for response: Summary. Copenhagen: WHO Regional Office for Europe; 2007, 1-60.
14. Paszkowski S. editor. [The new questions of food security in Europe and the world.] Proceedings of the $9^{\text {th }}$ Congress of Polish Economists; 2013 Nov 28-29; Warsaw, Poland. Polish.

15. The State of Food and Agriculture. Food and Agriculture Organization of the United Nations. Rome: FAO; 2013 http://www.fao.org/docrep/018/ i3300e/i3300e00.htm (access: 2017.06.26).

16. James WP. The epidemiology of obesity: the size of the problem. J Intern Med. 2008; 263(4): 336-52.

17. Pawlak K. [Food security in EU countries. Economics and organization of food economy.] Scientific Journal of Warsaw University of Life Sciences. 2012; 98: 39-51.

18. Berghöfer A, Pischon T, Reinhold T, Apovian CM, Sharma AM, Willich SN. Obesity prevalence from a European perspective: a systematic review. BMC Public Health. 2008; 8: 200.

19. Dinsa GD, Goryakin Y, Fumagalli E, Suhrcke M. Obesity and socioeconomic status in developing countries: a systematic review. Obes Rev. 2012; 13(11): 1067-1079.

20. Jarosz M, Rychlik E. Overweight and obesity among adults in Poland, 1983-2005. Adv Med Sci. 2008; 53(2): 158-166.

21. Śliwińska A. [Poles eat less fish and potatoes.] www.wiadomosci24.pl. (access: 2016.07.08). Polish.

22. Kowalowski P, Kowalowska M, Stanowska K, Burczyk J. [Natural sweeteners in terms of authorization for human consumption in Poland and EU countries.] Post Fitoter. 2004; 1: 4-9. Polish.

23. Myszkowska-Ryciak J, Harton A, Gajewska D, Bawa S. [Sweeteners in obesity prevention and treatment.] Kosmos - Problemy Nauk Biologicznych. 2010; 59: 365-374. Polish.

24. Knai C, Suhrcke M, Lobstein T. Obesity in Eastern Europe: an overview of its health and economic implications. Econ Hum Biol. 2007; 5(3): 392-408.

25. Pisa PT, Pisa NM. Economic growth and obesity in South African adults: an ecological analysis between 1994 and 2014. Eur J Public Health. 2017; 27(3): 404-409.

26. Egger G, Swinburn B, Islam FM. Economic growth and obesity: an interesting relationship with world-wide implications. Econ Hum Biol. 2012; 10(2): 147-153.

27. ALNohair S. Obesity in gulf countries. Int J Health Sci (Qassim). 2014; 8(1): 79-83.

28. Menifield CE, Doty N, Fletcher A. Obesity in America. ABNF J. 2008; 19(3): $83-88$

29. al-Shammari SA, Khoja TA, al-Maatouq MA, al-Nuaim LA. High prevalence of clinical obesity among Saudi females: a prospective, cross-sectional study in the Riyadh region. J Trop Med Hyg. 1994; 97(3): 183-188.

30. Cuevas A, Alvarez V, Olivos C. The emerging obesity problem in Latin America. Expert Rev Cardiovasc Ther. 2009; 7(3): 281-288.

31. Bocarsly ME, Powell ES, Avena NM, Hoebel BG. High-fructose corn syrup causes characteristics of obesity in rats: increased body weight, body fat and triglyceride levels. Pharmacol Biochem Behav. 2010; 97(1): 101-106.

32. Tappy L, Egli L, Lecoultre V, Schneider P. Effects of fructose-containing caloric sweeteners on resting energy expenditure and energy efficiency: a review of human trials. Nutr Metab (Lond). 2013; 10(1): 54.

33. Gopalan C. The changing nutrition scenario. Indian J Med Res. 2013, 138: 392-397.

34. Cybulska B, Szostak-Węgierek D. [Traditional Asian Diet. Why does it protect against myocardial infarction?] Probl Hig Epidemiol. 2012, 93: 172-177. Polish. 